\title{
Application of Sakamoto Math Method in Solving Mathematical Word Problems for Year 5 Pupils
}

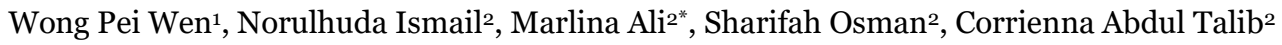 \\ ${ }^{1} S J K(C)$ Ming Chih, No.5, Jalan Hijauan 2, Horizon Hills, 79100 Puteri Iskandar, Johor \\ ${ }^{2}$ School of Education, Faculty of Social Sciences and Humanities, Universiti Teknologi Malaysia, \\ 81310 Johor Bahru, Malaysia
}

\begin{abstract}
Mathematical word problem solving skills has always been a concern in Malaysia because pupils are unable to cope with the word problems given. Thus, Sakamoto Math method was introduced to deal with the pupils' difficulties in solving word problems. The purposes of this study were to investigate the effectiveness of using Sakamoto Math method and to compare the pupils' performance in solving word problems between the application of Sakamoto Math method and conventional method. In addition, comparison of pupils' attitude towards the application of Sakamoto Math method and conventional method in solving word problems was also investigated. Quantitative methods were employed in this study. Year 5 pupils in a Chinese elementary school (SJKC), Nusajaya, Johor were assigned as a control group and an experimental group with 33 participants in each group. All the participations took part in the pre-test and post-test and the results were analysed through inferential statistics which are Paired Samples T-test and Independent Samples T-test. Pupils' attitude was then recorded in the questionnaire and analysed by using Wilcoxon-Signed Ranked test. There was a significant difference on pupils' performance and pupils' attitude between the application of Sakamoto Math method and conventional method. It proves that Sakamoto Math method is effective in solving word problems. In conclusion, this study suggests that different visualization approaches could be prepared to overcome the pupils' difficulties in solving word problems.
\end{abstract}

Key words: Mathematics, word problems, Sakamoto math method

\section{INTRODUCTION}

Mathematics is one of the crucial subjects in the school curriculum. The essential component of teaching mathematics is to foster the ability to use mathematics in solving daily problems and develop an attitude of seeking a logical explanation. In Malaysia's Primary Mathematics Teaching and Learning Syllabus (2013), the central focus of the framework is mathematical word problems solving where routine and non-routine problems must be introduced, and pupils need to be guided on how to solve them. These types of problems stress on conceptual understanding, skill proficiency, and mathematical processes.

Unfortunately, many students are still weak in solving word problems. According to Syed Abdul Hakim and Mohini (2010), pupils can understand the word problems given but, they are unable to apply the knowledge to the problemsolving process. It is said that Malaysian pupils are poor in solving word problems even though they have mastered the arithmetic skills (Mokhtar et al, 2001). Leong (2014) states that the reason for the students' failure to solve mathematical word problems is they used traditional approach such as key words strategy and computation skills.

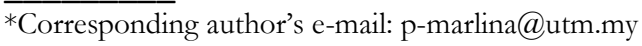


The National Council of Teachers of Mathematics (2002) claimed that students need to develop multiple strategies for solving problems such as looking for patterns or using diagrams to help students be successful problem solvers. Teachers who exhibit explicit strategies in problem solving benefit pupils in developing their problem-solving skills (Hembree et. al., 1992). Therefore, it is vital for teachers to keep on exploring and updating new problem-solving approaches to improve students' understanding and to master mathematical word problems.

One of the approaches is the visual approach which is a strategy to develop pupils' thinking skills using diagrams to represent a mathematical word problem (Smith, 2003). A visual approach called the Sakamoto Math method is used in this study to see if it improves students' problem-solving skills. The method was developed by Dr. Hideo Sakamoto from Japan in 1975 and has seen a tremendous growth during the past decade. There are three simple basic steps involved in the method which is grasp the relation, diagram, and writing. The following is an example of the Sakamoto Math method:

Problem: There are teachers and students who bought tickets. The price of each ticket for a teacher is RM2O while for a student is RM8. The number of tickets bought by the teachers is of the total number of tickets bought. The amount of money collected from the students is RM416 more thanfrom the teachers. What is the total amount of money collected?

\section{Solution:}
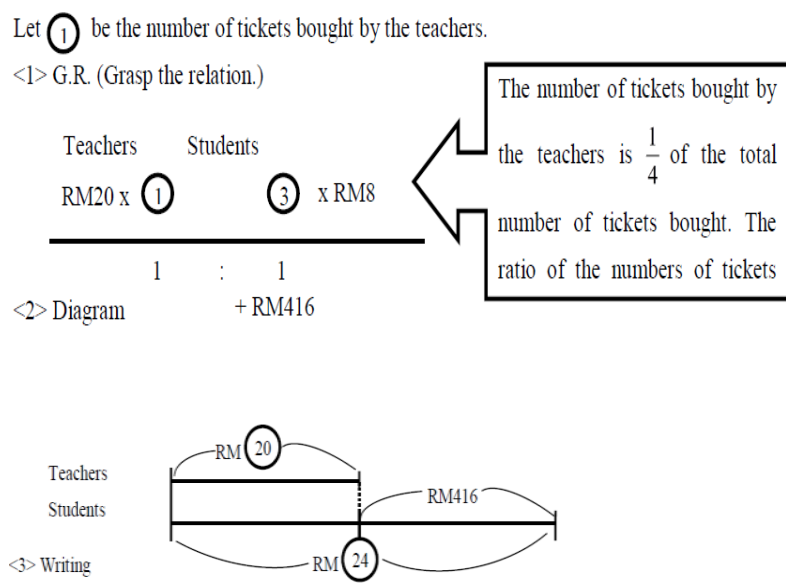

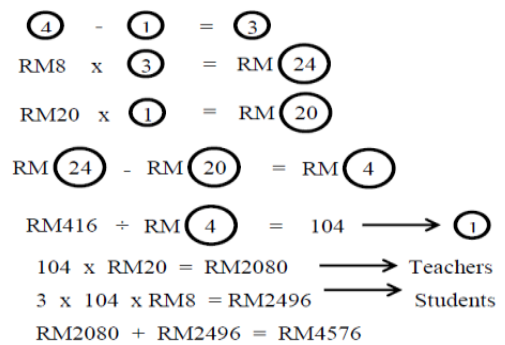

Answer: RM4576

The Sakamoto Math method is now being widely used in developed Asian countries like, Singapore, South Korea and Japan. However, in Malaysia's mathematics education, Sakamoto Math method is still not well known and not yet utilized in learning and teaching in school. Therefore, in this study, the effectiveness of using Sakamoto Math method in solving mathematical word problems in the Malaysian context is investigated.

\section{RESEARCH OBJECTIVES}

The objectives of this research are as follows:

i. To investigate the effectiveness of using Sakamoto Math method in solving mathematical word problems.

ii. To compare the performance of pupils between using Sakamoto Math method and conventional method in solving mathematical word problems.

iii. To compare the attitude of pupils towards the application of Sakamoto Math method and the conventional method in solving mathematical word problems.

\section{METHODOLOGY}

This study was conducted among Year 5 pupils at a Chinese medium elementary school, in Johor. In this study, a quasiexperimental pre-test and post-test control group design was employed to achieve the objectives. The samples chosen to take part in this study involved two classes. The two classes were class $5^{\mathrm{B}}$ (experimental group) with 16 male and 17 female students and class $5 \mathrm{C}$ (control group) with 18 male and 15 female students. Both groups have moderate level of achievement with 33 pupils each.

The participants in the experimental group learned to solve mathematical word problems with Sakamoto Math method and the participants in the control group used conventional method to solve mathematical word problems. 
A pre-test and post-test were given to both groups of participants with a total of ten items each. The items were developed based on the Mathematics Syllabus and Standard Document of Curriculum and Assessment (DSKP) of Year 5 Mathematics. The pre-test and post-test were administered to measure pupils' performance in solving mathematical word problems before and after using Sakamoto Math method and conventional method.

In the control group, conventional method which is Polya (2004) and chalk and talk method was introduced to the 33 participants. During the treatment, the researcher listed down Polya's four steps on the whiteboard which were 'understand the word problems', 'devise a plan', 'carry out the plan' and 'look back'. The researcher demonstrated examples from the Year 5 Mathematics textbook to enhance participants' understanding. Participants were requested to complete a set of treatment tasks which contained twelve mathematical word problems over four sessions.

In the experimental group, Sakamoto Math method was used, also over four treatment sessions. The three steps of Sakamoto Math were listed on the whiteboard in every session. Examples were given in each session with the help of a diagram model. Participants in the experimental group were also requested to complete the same twelve mathematical word problems as the control group but, by using Sakamoto Math method.

Finally, questionnaires on attitude towards the Sakamoto Math method and conventional method were distributed to the experimental group, after the post-test. Attitude is a psychological tendency expressed by evaluating a particular entity with some degree of favour or disfavour (Eagly and Chaiken, 1993). It is a judgment constructed based on beliefs and readiness and are primary indicators of a person's intent to perform a behavior (Ajzen, 1991). The items in the attitude questionnaires are a five-point Likert-type. Examples of items in the questionnaire for the Sakamoto Math method and Conventional approach are as follows:

1. The Sakamoto Math Method is an interesting method to solve mathematics problems

2. Sakamoto Math Method helps me to solve mathematical word problems easily

3. Conventional method is an interesting method to solve mathematical word problems.

4. Conventional method helps me to solve mathematical word problems easily.

\section{DATA ANALYSIS}

The data gathered was analysed using Statistical Package for the Social Science (SPSS). Paired Sample T-Test was conducted to analyse the effectiveness of Sakamoto Math method based on the performance of the experimental group. An Independent Samples T-test was conducted in order to compare the performance of the control group and the experimental group in the pre-test and post-test. Wilcoxon Signed Rank test was used to measure the mean ranks of participants' attitude towards Sakamoto Math method and conventional method

\section{RESULTS}

\section{A. To investigate the effectiveness of using}

Sakamoto Math method in solving mathematical word problems

A normality test was conducted with the pre-test and posttest scores of the experimental group and the distribution of the scores were found to be normal with p>0.05 (Table 1). This means that the data gathered fulfils the normality assumption of the t-test.

From table 2, the mean score for the pre-test $(\mathrm{M}=67.9470, \quad \mathrm{~s}=16.20459)$ and post-test $(\mathrm{M}=82.8636$, $\mathrm{s}=9.88431$ ) shows an increase of 14.9166. It is concluded that there is a significant difference between pupils' performance before and after Sakamoto Math method in solving mathematical word problems $(\mathrm{t}(32)=-5.333, \mathrm{p}<$ o.05, two tailed).

Table 1. Normality Test results

\begin{tabular}{|l|c|c|c|}
\hline \multirow{2}{*}{} & \multicolumn{3}{|c|}{ Shapiro-wilk } \\
\cline { 2 - 5 } & Statistic & df & Sig. \\
\hline Pre-test Sakamoto Math Method & 0.970 & 33 & 0.489 \\
\hline $\begin{array}{l}\text { Post-test Sakamoto Math } \\
\text { Method }\end{array}$ & 0.963 & 33 & 0.321 \\
\hline
\end{tabular}


Table 2. Paired Samples T-test Statistics

\begin{tabular}{|c|l|l|l|l|l|c|}
\hline & Mean & N & Std. Deviation & t & df & Sig. (2-tailed) \\
\hline Pre-test & 67.94 & 33 & 16.20 & & & \\
& & & & & \\
Post-test & 82.86 & 33 & 9.88 & & & \\
\end{tabular}

\section{B. To compare the performance of pupils} between using Sakamoto Math method and conventional method in solving mathematical word problems

Before conducting the Independent Sample T-test, Levene's Test for Equality of Variances was carried out (Table 3) with the result showing $\mathrm{p}=0.867 ; \mathrm{p}>0.05$. Thus, it is assumed the variances between these two groups are equal which means that the students in the control group and the experimental group are of equivalent performance.

Table 3. Levene's Test for the Equality of Means

\begin{tabular}{|l|l|l|}
\hline \multirow{2}{*}{$\begin{array}{l}\text { Equal variances } \\
\text { assumed }\end{array}$} & $\begin{array}{l}\text { Levene's test for Equality of } \\
\text { Variances }\end{array}$ \\
\cline { 2 - 3 } & $\mathrm{F}$ & Sig. \\
\hline
\end{tabular}

Table 4. Independent Samples T-test Statistics

\begin{tabular}{|l|l|l|l|l|l|}
\hline Groups & Mean & Std. Deviation & d & df & Sig. (2-tailed) \\
\hline Control & 68.37 & 9.84 & \multirow{2}{*}{-5.96} & 64 & \multirow{2}{*}{0.00} \\
\cline { 1 - 3 } Experimental & 82.86 & 9.88 & & \\
\hline
\end{tabular}

Based on the result shown in table 4, the mean scores of the post-test obtained in these two groups were different where the control group $(\mathrm{M}=68.37, \mathrm{~s}=9.84)$ demonstrated poorer performance than the experimental group $(\mathrm{M}=82.86$, $\mathrm{s}=9.88)$. The t-test shows $\mathrm{t}(64)=-5.968, \mathrm{p}<0.05$, two tailed which suggest that using Sakamoto Math method has a positive effect on pupils' performance in solving mathematical word problems. Specifically, the results suggest that by applying Sakamoto Math method in solving mathematical word problems, the pupils' score will increase compared to the pupils who were using conventional method to solve mathematical word problems.

\section{To determine the attitude of pupils towards} the application of Sakamoto Math method and the conventional method in solving mathematical word problems
Table 5. Wilcoxon Signed Rank Test Statistic

\begin{tabular}{|l|c|c|l|}
\hline Methods & $\mathrm{N}$ & $\begin{array}{c}\text { Mean } \\
\text { Rank }\end{array}$ & $\begin{array}{l}\text { Asymp. Sig. } \\
\text { (2-tailed) }\end{array}$ \\
\hline $\begin{array}{l}\text { Conventional } \\
\text { method } \\
\begin{array}{l}\text { Sakamoto Math } \\
\text { method }\end{array}\end{array}$ & 33 & 8.10 & 0.000 \\
\hline
\end{tabular}

Table 5 shows the attitude of participants from the experimental group towards the application of conventional method (mean rank $=8.10$ ) is lower than Sakamoto Math method (mean rank=18.06) in solving mathematical word problems. Besides that, the asymptotic significance (two-tailed) shown in Table 6 is $\mathrm{p}=0.000, \mathrm{p}<$ 0.05. Thus, there is a significant difference of pupils' attitude towards using Sakamoto Math method and conventional method in solving mathematical word problems. 


\section{DISCUSSIONS}

The result of analysis shows a few positive changes. There was an increase on the pupils' performance in solving mathematical word problems after applying the Sakamoto Math method in the treatment. The pupils in the Sakamoto Math method group also performed better in solving mathematical word problems compared to the conventional method.

Pupils were found to be more confident in solving mathematical word problems as Sakamoto Math method teaches pupils to grasp the relationship of the questions and draw the linear diagrams when solving the mathematical word problems. The three simple steps also encouraged the pupils' positive attitude towards problems solving concept.

The students have better understanding in solving the mathematical word problems when they applied Sakamoto Math method because they were given the opportunity to transform the word problems situation into diagrams and apply their mathematical knowledge through exploring the word problems situation (Lester and Kehle, 2003). This allowed them to enhance their higher order thinking skills and apply their critical and logical thinking skills independently without spoon-feeding from the teacher. Also, it encourages students to form long term memory of mathematical knowledge.

Aside from that, through the survey, most of the pupils gave positive feedback towards Sakamoto Math method compared to the use of conventional method. Through the analysis, it can be concluded that Sakamoto Math method is an interesting and suitable method to solve mathematical word problems and is able to enhance pupils' critical thinking skills. Based on the analysis of questionnaires, pupils were clear about the three simple steps of Sakamoto Math method and were ready to use this method in their problem-solving worksheets in the future. This is in line with Moyer, Bolyard and Spikell (2002) in their research that by using visualization strategy in solving mathematical word problems, the pupils' learning became more enjoyable and pupils perceive that it stimulated learning. In conclusion, the application of Sakamoto Math method has showed its effectiveness in solving mathematical word problems and this method seems to attract the pupils' interest in the lesson.

\section{CONCLUSIONS}

Having excellent problem-solving skills can promote high performance in solving mathematical word problems in pupils. It is a way for pupils to compete globally in education. As suggested by Woodward et. al., (2012), teachers need to integrate the activities of problem solving in their instructions and incorporate visual aids such as diagrams into the mathematical word problems taught. Besides, Papic (2012) suggested that by promoting mathematical problem-solving skills which involve higher order thinking skills at the early age, can prompt their learning opportunities in solving mathematical word problems.

The use of Sakamoto Math method seems to trigger students thinking skills to solve mathematical word problems. This method can be used in mainstream class and low achievement class so that the learning process becomes more meaningful. Other than that, Sakamoto Math method can also be implemented in secondary schools according to their proficiency level. Pupils can share the knowledge they gained in Sakamoto Math method with their peers during group discussions. Indirectly, it will encourage pupils to be more independent as well as responsible towards their own learning in solving mathematical word problems.

Although conventional method is a strategy used by most mathematics teachers for certain period of time in their teaching of solving mathematical word problems, teachers should put more effort in preparing their mathematics lesson and always keep themselves up to date. Pupils will lose interest in learning as well if the same approaches are repeated. Teachers should try to apply visualization strategy such as Sakamoto Math method so that pupils can understand better as they learn by drawing a diagram to picture the word problem's situation.

\section{ACKNOWLEDGEMENT}

The authors would like to express sincere gratitude to Universiti Teknologi Malaysia (UTM) for their financial funding through RUG Vote No Q.J1300oo.2531.18H44. 


\section{REFERENCES}

Ajzen, I. 1991, The theory of planned behavior. Organizational behavior and human decision processes, 50, 179-211.

A.H. Eagly \& S. Chaiken. 1993, The psychology of attitudes. Fort Worth, TX: Harcourt,794 pp.

Hembree, R. 1992, Experiments and relational studies in problem solving: A meta-analysis. Journal for Research in Mathematics Education, 23(3), 242-273.

Ministry of Education 2013, Mathematics Syllabus and Standard Document of Curriculum and Assessment Year 5. Kuala Lumpur: Curriculum Development

Leong, Y. H., Tay, E. G., Quek, K. S., Toh, T. L., Toh, P. C., Dindyal, J., \& Yap, R. A. S. 2014, Making mathematics more practical: Implementation in the schools. Singapore: World Scientific.

Lester, F. K., \& Kehle, P. E. 2003, From problem solving to modeling: The evolution of thinking about research on complex mathematical activity. In R. A. Lesh \& H. M. Doerr (Eds.), Beyond Constructivism: Models and Modeling Perspectives on Mathematics Problem Solving, Learning, and Teaching (pp. 501-517). Mahwah, NJ: Lawrence Erlbaum Associates.

Ministry of Education. 2012, Dasar Pendidikan Kebangsaaan. Putrajaya: Ministry of Education.

Mokhtar I., Aminah A. dan Lim T. 2001, Monitoring mathematical word problem solving weaknesses of primary school children. Kertaskerja yang dibentangkan di Seminar Malaysian Educational Research Association (MERA), Universiti Sains Malaysia, Pulau Pinang.

Moyer, P. S., Bolyard, J. J., \& Spikell, M. A. 2002, What are virtual manipulatives? Teaching Children Mathematics, 8(6), 372-377.

National Council of Teachers of Mathematics 2002, Principles and standards for school mathematics. Reston, VA: Author.

Papic, M. M. 2013, Improving Problems Solving Skills among Children. Advances in Mathematics Education, 253 - 281. Springer Science+Business Media.

Polya, G. 2004, How to Solve it: a new aspect of mathematical method. Princeton, NJ: Princeton University Press.

Smith, S.M. 2003, The constraining effects of initial ideas. In P. Paulus \& B. Nijstad (Eds.), Group creativity:
Innovation through collaboration (pp. 15-31). Oxford, England: Oxford University Press.

Syed Abdul Hakim S. Z dan Mohini M. 2010, Keupayaan dan Sikap dalam Menyelesaikan Masalah Matematik BukanRutin. Jurna lTeknologi, 53 (SainsSosial).47-62. Universiti Teknologi Mara.

Woodward, J., Beckmann, S., Driscoll, M., Franke, M., Herzig, P., Jitendra, A., Koedinger, K.R., \& Ogbuehi, P. 2012, Improving mathematical problem solving in elementary school education: A practice guide (NCEE 2012-4055). Washington, DC: National Center for Education Evaluation and Regional Assistance, Institute of Education Sciences, U.S. Department of Education. 